\title{
Construction of Humanities Curriculum System in Fire Colleges and Universities at the View of Human Science
}

\author{
Hongbo Zhou \\ Training department Kunming Fire Service Training School, Kunming, China \\ zhouhongboxf@126.com
}

\begin{abstract}
Keywords: View of human science; Fire colleges and universities; Talents training; Humanities course
\end{abstract}

\begin{abstract}
The realistic fire pattern requires fire officers in actual combat to have high professional ability, in addition more to embody rich humanistic quality in the occupation. Based on the reality of humanism deficiency and situation urgency in the process of modern command officer training, it is necessary to deeply reflect the present situation and value connotation of humanities course, scientifically construct humanities courses system in fire colleges and universities under new situations, strengthen the basic compositions of humanities courses, reform the waysto improve humanistic education and the humanities accomplishment, and steadily push forward the fire officer training to integrate into the basic value pursuit of humanistic education.

With the change of the international economic strategy and the transformation of the intellectual economy, in addition facing the kaleidoscope of ever-changing and various social phenomena and overwhelmed multiple thoughts, some issues about "humanism" have also prospered, whose common connotation embodies the importance of paying attention to the use of "humanism" in modern personal training.
\end{abstract}

\section{The Basic Connotation of Humanism Idea}

For many years, the expressions of "humanism" have been divisive in academic circles and failed to reach agreement yet, whose research is lack of corresponding preparation but unwilling to remain out of the limelight. After general analysis of various descriptions and opinions about "humanism", a basic concept can be summarized preliminarily as follows: humanism is a vivid process of internalization from "how a man" to "how to do things", recording the individual behavior track and shaping the images by means of act to reflect individual life, thoughts and feelings. It is a self-reflection and self-enhancement progress facing the individual and the world, providing training object with strong penetration and influence. Education of "humanism" in colleges and universities is concentrated on the concrete implementation of how to pay attention to, respect, concern and care for the talents.

\section{The Urgency of Strengthening Humanistic Education in Colleges and Universities}

As a turbulent and hot issue, the basic element weakness of the humanities quality in the contemporary Chinese youth has brought highly attention of society and related industry, inducing theoretical discussion and practice explore in the field of humanities education among social all circles including fire fighting colleges and universities.

The Salient Situation of Current Education. Contemporarily, young students are generally lack of humanistic value internalization and have no time to take into account the humanistic quality connotation promotion. Phenomena of lacking humanistic spirit are shocking, such as the pursuit of moral beliefs and personality, the desire of value, freedom, equality and justice, respect for human, looking forward to and praise of human subjectivity, reflection on life, death, faith, happiness and survival significance of human beings, ultimate concern of human beings and so on. Under big data diversified background and faced with modern knowledge economy as well as network information carriers such as micro-blog and WeChat, students of colleges and universities are impacted by mammonism, individualism and hedonism, keeping indifferent to various crisis of 
human and nature, human and society, human and civilization, human and human moral, in addition to national survival and prosperity. Most young students are used to have weak ideals and beliefs, low personality and vague value of life, only caring about personal future and long-term development and avoiding thinking about life.

The Urgency of Strengthening Humanistic Education. Since education reform and talents training are complex systems, those related humanities courses in fire fighting colleges and universities should be unified with them. Neither only benefit education nor only intelligence education is suitable, some link or process cannot be accomplished overnight. For example, for educated objects, the neglect of the humanities courses fusion with professional courses means the loss of their culture value and existence fundament, for social groups, means the loss of value belief and humanities courses can be extended deep chain fracture, for the employing unit, means no grade or confused. Due to the narrow view of quick buck education despising human science, humanity and education, it is a fact that factor evaluation in education is with knowledge, technology and theory, but without wisdom, culture and practice. Therefore, it is of great importance to build a scientific and reasonable humanities course system for colleges and universities to transit themselves scientifically and rationally to the age of post material value orientation of the times and to achieve the training target with soul, ability and feelings and morality.

\section{Construction of Curriculum System on the Basis of Talents Demand}

Colleges and universities should pay attention on the coordination of professional education should with humanities education, integrating the "harmonious person" with the "human science" to become a harmonious development of the fire fighting cause. "What kind of people should be, which kind of ability should have, what kind of curriculum should be offered" also embodies the view of curriculum. It is both the requirement for talents of social development and the professional value expression of the fire fighting work to integrate humanistic education with education system, not only the adjustment of inclination to overlook humanities education, but also directly related to the fire officers' training. It is an inevitable requirement in the process of education to keep the system integrity of training target, curriculum and textbook reform to achieve the real value education of humanities courses.

Embodiment of the Humanistic Connotation in the Training Objectives. In the past 20 years of Chinese fire academy education, the talent training goal and philosophy of some colleges and universities are vague, who are anxious to achieve quick success, focuses on the technology, while neglect to focus on the individuals soul, personality and future development strategy, leading to a considerable number of people lacking basic quality of "how to serve the society" which is requisite for a modern fire police officer, instead of being superficial, impetuous, no creativity and no gas, etc.

Talents cultivation is fundamental for the future development of the fire cause. Therefore, combining with training objectives, development requirements, subject characteristics and training direction, efforts should be spent to cultivate, create and enhance humanities curriculum according with the requirements of the times characteristics. Humanities courses system should be set up by searching, refining and producing characteristics from its own history, present situation and cultural environment to realize the sustainable development. Research and practice has proved that "education of excellent fire fighting command talent" is just a special mission in the education process and a subject of fire education. Particularly in the key training stage of colleges and universities academic education, it can't have a trace of slack, since the physical and mental conditions of training target have been mature, together with the formation of outlook on life and values. As Einstein said that the purpose of the school should always be young people leaving school as a harmonious person, not just as an expert. Moreover, education of people with professional knowledge can produce a useful machine, but is not enough to provide harmonious development. The goal is to provide true and effective nutrition for the spiritual growth of the modern police officers. Based on this, fire colleges and universities should constantly revise too 
high or vague objectives in the process of education, first "people", and then "soldiers", the last "police officer". Through education, in addition to qualitative change of professional quality, personalities of how to behave or how to do can be improved, since "human" harmonious and all-round development is of more connotations.

Coherence of the Humanities Courses in the Curriculum. In some fire colleges and universities, general knowledge courses such as College Chinese, Philosophy, Laws and so on are set as stepping stone, but these courses are useless, lack of coordination and without interference. Hence, humanities courses lack coordination with other courses, especially with the professional courses. Even political theory replaces humanities courses and phenomenon that students want to learn but fail to learn, making them pay no attention to humanistic education appears. For example, to seek the answer for a literary problem should start from history, politics and philosophy. However, teachers of the basic course are usually responsible for College Chinese curriculum, while courses of History, Politics, Philosophy and so on are often opened by teachers of political theory.

Without many classes or related courses to teach knowledge about the formation of literature, source of writer's thought, college teachers only pay attention to the text and fail to explain some major issues, which greatly shrinking general courses usually with most images and decreasing students' interest and professional realization ability year after year.

Based on the training practice and social needs of modern fire officers, a compound structure with effective scale can match richness and polysemy connotation of humanities courses. For instance, Writing, Speaking, Aesthetics, Philosophy and other elective courses presenting humanities education are still enlarge courses of College Chinese course. Writing textbooks of humanities curriculum should fix with the emphasis of College Chinese, using those important chapters and writers in College Chinese textbook as main teaching points. For example, Tao Yuanming's poems can't be taught through only by 2 hours, since we can't omit the contradiction between being an official and being a hermit tangled in the author's heart, which was oriented from Confucianism and the social background of Eastern Jin Dynasty. Therefore, humanistic course system of College Chinese can be built from the humanistic knowledge, spirit and methods, teaching the influence of Chinese Confucianism to the ancient Chinese intellectuals in Philosophy course, also quoting Tao Yuan Ming, Su Shi and Xin Qiji and so on.

Emphasizing Innovation in Humanities Textbook Reform. Since teaching is an organic unity of textbook, teacher and students, the reform of textbook is a key link in the construction of college education curriculum. By now, humanities education on the whole has not fully digested new educational idea and teaching method of discussion yet, which failed to spread in corresponding colleges and universities. Certainly, quality education and training is a long term work. High level teaching content can reflect the forefront questions, trends and achievements of human science research, answer puzzling social problems and cultural confusion in the real world, and reflect the identified development law of modern humanistic quality. It is an effective way to improve the level and quality of teaching to embody the advanced education concept by the textbook. Hence, curriculum construction should rely on textbook and gather experts of education to carry out reform.

There are many but most similar textbooks of human course in fire colleges and universities. Textbook innovation should pay attention to the style and content, especially the improvement of connotation to match the development law of modern fire control officer training, to promote the sublimation of emotion, attitude and values. Textbook should be a certain open, avoiding wishful and boring preaching to escape from the trap of cancelling humanistic tradition. Supplementary materials matching with textbooks should also be complete to provide extracurricular reading materials and various teaching designs. Using interaction systems between teaching and learning, subjective and objective, the humanistic textbook reform promotes the training object's personal experience to the excellent cultural tradition of reality. In recent years, colleges and universities carry out teaching models of case teaching, seminar teaching and so on, which fail to to fully integrate with the teaching practice. According to the openness and diversity characteristics of humanities curriculum, they should be agreed by the humanities curriculum teaching objectives. 
Advanced teaching methods and practical experience should be applied to promote the reform of humanities curriculum textbook. When selecting humanities textbooks, it is necessary to integrate training target and prepare some alternative plans from the supplementary teaching materials for the unique receptive psychology diversified by mental age, educational background and life experience. Not only teaching method is ensured to be implemented in the form, but also the noble and scientific moral of modern fire officers is established. Moreover, the Chinese excellent traditional culture promotes the humanities quality and teaching quality in methodology affect.

\section{Conclusion}

It is of great significance to train excellent modern police officers with high-quality under new situations to match social needs and overcome puzzle at humanity education in the human science education of modern fire officer culture in post material age. As an important carrier of modern people's personality, the humanities curriculum system embodies the basic quality of a modern people in human science education and the value orientation coordinate for the perspective of the society development. It is the responsibility of fire colleges and universities to provides a good environment and create a thick atmosphere for the health comprehensive development of modern fire police, which no doubt should be realized by the humanities curriculum, leading modern fire officers to get profound understanding in the tangible and intangible value resources of the humanities curriculum, reaching the final realization of a win-win connotation between professional education and humanities education.

\section{References}

[1] Zhu Ruke. Military College Education Research [M]. Publishing House of Sea Tides, 1990

[2] Liu Hai. Military Academy Synthesis System [M]. Military Science Publishing House, 2001

[3] Yuan Jiankang. Quality Education and Practice in Military Academy [M]. Military Science Publishing House, 2003

[4] Shi Chunlin. Humanistic Quality-oriented Education of College Students and Construction of a Harmonious Society [J].Journal of hefei University of Technology, 2007, 21(4): 95-98

[5] Shi Jinghan. Cultivation of Humanities Spirit, indispensable Teaching objectives for Integrated Science [J]. Global Education,2001.9

[6] Liu Zhiyun. On harmonious Society and Harmonious University[J]. Research in Teaching, 2009, 32(4): 